\title{
Adherence of older women with strength training and aerobic exercise
}

\author{
This article was published in the following Dove Press journal: \\ Clinical Interventions in Aging \\ 14 February 2014 \\ Number of times this article has been viewed
}

\section{Alexandra Miranda \\ Assumpção Picorelli \\ Daniele Sirineu Pereira \\ Diogo Carvalho Felício \\ Daniela Maria Dos Anjos \\ Danielle Aparecida Gomes \\ Pereira \\ Rosângela Corrêa Dias \\ Marcella Guimarães Assis \\ Leani Souza Máximo \\ Pereira}

Graduate Program in Rehabilitation Sciences, Department of Physical

Therapy, Universidade Federal de Minas Gerais, Belo Horizonte, Minas Gerais, Brazil
Correspondence: Alexandra Miranda Assumpção Picorelli

Departamento de Fisioterapia da Universidade Federal de Minas Gerais, Av Antônio Carlos, 6627, CEP 31270-90I, Belo Horizonte, Minas Gerais, Brazil

Tel +553 3 34994783

Fax +553 3 3499478 I

Email alexandram.fisio@gmail.com
Background: Participation of older people in a program of regular exercise is an effective strategy to minimize the physical decline associated with age. The purpose of this study was to assess adherence rates in older women enrolled in two different exercise programs (one aerobic exercise and one strength training) and identify any associated clinical or functional factors.

Methods: This was an exploratory observational study in a sample of 231 elderly women of mean age 70.5 years. We used a structured questionnaire with standardized tests to evaluate the relevant clinical and functional measures. A specific adherence questionnaire was developed by the researchers to determine motivators and barriers to exercise adherence.

Results: The adherence rate was $49.70 \%$ in the aerobic exercise group and $56.20 \%$ in the strength training group. Multiple logistic regression models for motivation were significant ( $P=0.003)$ for the muscle strengthening group $\left(R^{2}=0.310\right)$ and also significant $(P=0.008)$ for the aerobic exercise group $\left(R^{2}=0.154\right)$. A third regression model for barriers to exercise was significant $(P=0.003)$ only for the muscle strengthening group $\left(R^{2}=0.236\right)$. The present study shows no direct relationship between worsening health status and poor adherence.

Conclusion: Factors related to adherence with exercise in the elderly are multifactorial.

Keywords: older women, adherence, therapeutic exercises

\section{Introduction}

The growth of elderly populations is a global phenomenon, and these changes have been radical and accelerated in Brazil. Conservative projections indicate that Brazil will have the sixth largest elderly population in the world by 2020 , with over 30 million people classified as elderly. ${ }^{1,2}$

Recent studies have shown that chronic disease and incapacity are not inevitable consequences of the aging process. Prevention is effective in all age groups, even in the latest stages of life. ${ }^{1}$ Therefore, an emphasis on prevention is important in terms of changing the current framework of incapacity and comorbidity. Loss of muscle quality and quantity and reduced muscle strength with advancing age contributes significantly to a decline in the performance of activities of daily living (ADL), resulting in reduced mobility, slower gait speed, and changes in balance as well as an increased risk of falls. Thus, there is an increase in incapacity. ${ }^{2,3}$

The benefits of exercise in the elderly are well established, and include reduced fragility, increased gait speed, and increased performance of ADL. Exercise also provides independence and improves quality of life. ${ }^{3}$ Elderly people who undertake a regular exercise program show better balance and have a reduced risk of falling. ${ }^{4,5}$ 
Adherence is defined as the number of sessions attended divided by the number of sessions offered, and according to the literature, this relationship is frequently very low. ${ }^{6}$ The evidence suggests that $50 \%$ of people who begin a program of exercise discontinue within 6 months. ${ }^{7-9}$ An adherence level of at least $80 \%-85 \%$ is recommended if the results of an intervention are to be satisfactory and if the intervention is to have therapeutic value. ${ }^{10}$

Another important concept for exercise intervention is retention. This involves maintenance of the individual bond to a program of exercises as an experimental or clinical model. An individual may be linked to an exercise program throughout the period and without proper frequency, ie, without satisfactory adherence. ${ }^{7}$

Kruger et al evaluated 6,000 elderly subjects and found that only $11 \%$ reported regular participation in a muscle strength training program. ${ }^{11}$ This study, which included a significant number of participants, showed the difficulties of adherence with exercise programs among the elderly. Further, in a study investigating elderly subjects with chronic pain, Sluijs et $\mathrm{al}^{12}$ showed that $70 \%$ of participants failed to adhere to a program of therapeutic exercise in the long-term. In addition, Taylor et $\mathrm{al}^{13}$ found that rates of adherence with exercise among elderly individuals were approximately $14 \%$ to $17 \%$.

Health professionals have made considerable effort to identify factors related to adherence with therapeutic exercise by elderly people, in view of the fact that it could allow for greater success of proposed treatments, maintain patient independence, increase muscle capacity and function, and minimize ongoing use of health care services. ${ }^{14}$ However, there is no consensus in the literature as to the factors that contribute to adherence with exercise programs in the elderly. In addition, there is a lack of standardized instruments for measurement of compliance. . $^{4,6,15}$

Social, economic, and cultural factors may influence adherence, so surveys of adherence should be performed locally. We cannot extrapolate the results of international studies to the Brazilian population, which exists in a completely different context. Further, there have been few studies in which adherence has been a primary outcome and in Brazil there is no similar research. The objectives of the present study were to identify rates of adherence and retention in elderly women participating in aerobic exercise or muscle strength training programs and to identify the motivators, barriers, and clinical/functional factors associated with adherence of elderly women with therapeutic exercise programs.

\section{Materials and methods}

This study was approved by the ethical and research committee of the Federal University of Minas Gerais (ETIC $38 / 2010$, with approval of an addendum). Details of the original project are in the Registry of Brazilian Clinical Trials (REBEC RBR9v9cwf).

\section{Sample}

Our study population comprised a convenience sample of women aged 65 years or older who lived in the community and were recruited by advertising among third-age groups and associations as well as in newspapers. The sample was not randomized, and the study design involved development of two exercise programs at different points in time. The first volunteers were allocated to a muscle strengthening group, and when enough participants had been enrolled in this group, subsequent volunteers were allocated to an aerobic exercise group. All participants provided their voluntary informed consent. We excluded anyone who showed cognitive changes detectable on the Brazilian version ${ }^{16}$ of the MiniMental State Examination. We also excluded subjects who had undergone orthopedic leg surgery, those with a history of fracture in the previous 6 months, those with a neurological disorder, and those with clinical or sensory conditions that precluded their participation in an exercise program.

We calculated the sample size using the following regression model formula: $10(\mathrm{k}+1)$, in which $\mathrm{k}$ represents the number of explanatory variables in the model. ${ }^{16,17}$ For each intervention group, three models of regression were used to explain adherence or failure to adhere. The ten explanatory variables used for the model, chosen from the theoretical framework, were: the Timed Up and Go test, ${ }^{18}$ the Sit-to-Stand test, ${ }^{19}$ habitual gait speed, ${ }^{20,21}$ history of falls, presence of pain, number of comorbidities, self-rated health, ${ }^{22,23}$ depressive symptoms, ${ }^{24}$ self-rated stress, ${ }^{25}$ and cognitive capability. ${ }^{16}$ The other two models were constructed to include 13 motivators and 12 barriers according to the adherence questionnaire developed by researchers. Thus, $10(13+1)=140$ elderly women were necessary for each group.

\section{Survey instruments}

For sample characterization, we obtained sociodemographic data and information relevant to the clinical status of our elderly female study participants using a questionnaire developed by the researchers. Folstein et $\mathrm{al}^{26}$ recommended the Mini-Mental State Examination as a useful screening tool for detection of cognitive impairment in both the clinical and research setting. In 1994, Bertolucci et al published 
a version of the Mini-Mental State Examination adapted for the Brazilian population. ${ }^{16}$ In the present study, we used this tool as a reference for cutoff points, with a score of 13 for illiterate elderly and a score of 24 for educated elderly, given that previous studies have demonstrated this scale to have good reliability. ${ }^{27,28}$

In the present study, the Mini-Mental State Examination was used for subject exclusion and test scores were used as an explanatory variable in the regression model to evaluate the association between adherence and cognitive capacity in the study subjects..$^{29,30}$

The Geriatric Depression Scale (GDS) was used to screen for the presence of depressive symptoms, and was administered by structured interview. The 15-item GDS scale (GDS-15) is a short version of the original scale developed by Sheikh and Yesavage ${ }^{24}$ and contains items that are most strongly matched with a diagnosis of depression.

Previous studies have demonstrated that symptoms of depression can interfere with the undertaking of physical exercise and that elderly people experiencing mood changes and general depressive symptoms are less committed to the intervention and therefore the results are worse.

A 14-item scale of perceived stress was used to evaluate the level of stress in our study participants. This scale evaluated three factors considered to be the main components in the experience of stress, ie, the extent to which individuals rate their lives as unpredictable, uncontrollable, and overloaded. ${ }^{31}$ Henry et $\mathrm{al}^{32}$ found that patients who are asked to perform many exercises do not perform as well in terms of adherence. In addition, a prescription for excessive exercise can negatively affect adherence in elderly women. ${ }^{10,25}$

Self-evaluation of health status was determined by a simple question, "In a general way, how do you consider your health?". The answer to this question is one of the most commonly used indices in gerontological research and is an important indicator of functional decline and consequent restriction of activity. ${ }^{22,23}$ The literature demonstrates that elderly women with greater adherence are the most likely to get involved in other programs for promoting health, and that this is directly linked to their behavior, perception of their health, motivation, and self-efficacy. ${ }^{30}$

\section{Tests of function}

We selected three tests to evaluate functional capacity, all of which can be carried out simply and rapidly in clinic practice; these tests are also valid and reliable in the elderly population. We used these tests because elderly people with lower functional performance find it more difficult to develop regular exercise habits. ${ }^{14}$

We measured walking speed over 10 minutes to evaluate habitual gait speed. The participants were instructed to select their own walking speed. Pace was registered only in the middle $6 \mathrm{~m}$ of a lane, identified by tape markings, to avoid acceleration and deceleration bias. ${ }^{20,21,33}$

We used the Timed Up and Go test to evaluate mobility. This test records the time taken for a subject to stand up without using their arms from a sitting position in a standardized chair with a seat height of $45 \mathrm{~cm}$, walk $3 \mathrm{~m}$, turn around, and return to the seat and sit down again. This test has high interrater reliability (intraclass correlation coefficient 0.99 ) and intrarater reliability (intraclass correlation coefficient 0.99). ${ }^{18,34}$

To evaluate functional performance in terms of sitting and standing, which is an indirect measure of strength in the legs and is associated with decline of function and capability, we used the Sit-to-Stand test with a standardized chair of $45 \mathrm{~cm}$ and floor height as the reference. ${ }^{19,20}$

\section{Adherence questionnaire}

There are no previous examples of adherence questionnaires validated and adapted for an elderly population in Brazil. ${ }^{35}$ Therefore, we developed our own adherence questionnaire based on the literature and on the cultural, economic, and social context of Brazil. This questionnaire contained questions on the following three components: reasons for lack of attendance at sessions, motivating factors, and barriers to adherence with the different therapeutic exercise programs. As part of the development of this instrument, we trialed the questionnaire in ten elderly subjects participating in a physical exercise program. The necessary adjustments were made until the final version of the questionnaire was ready for use. Intraobserver and interobserver variability were assessed by the kappa coefficient and this resulted in excellent intraobserver reliability (kappa coefficient 0.846 ) and interobserver reliability (kappa coefficient 0.822 ).

\section{Procedures}

First, the Brazilian version ${ }^{26}$ of the Mini-Mental State Examination was used to exclude elderly women with cognitive impairment. This was followed by a clinical sociodemographic questionnaire in the form of a structured interview for characterization of the sample. ${ }^{16}$ For the functional tests, all participants were given the same verbal instructions and the investigators demonstrated tests before the participants carried them out. 
After the initial evaluation, the elderly women were allocated to a therapeutic exercise group, ie, either muscle strength training or aerobic exercise. Each program lasted 10 weeks and comprised three sessions weekly, each lasting approximately 50 minutes and guided by physiotherapists and members of the research team.

The muscular strength training group carried out leg exercises involving concentric and eccentric contraction with resistance, with the load tailored to meet individual requirements and ability. The loads were progressively increased over the 10 weeks of the training program. The load appropriate for each participant was defined by calculation of maximum resistance. ${ }^{36}$

The aerobic exercise program was based on a protocol recommended by the American College of Sport Medicine (2009) for the elderly, and comprised 5 minutes of warming up, 40 minutes of aerobic activity, including exercises for the arms and legs while walking, orthostatic exercise, and a 5 -minute recovery period. Before and after each exercise session, blood pressure, and heart rate were measured. In addition, heart rate monitoring was undertaken in participants allocated to aerobic exercise to ensure that the program was safe for them and that their training range was appropriate. ${ }^{37}$

After completion of the 10-week training program, the volunteers were re-evaluated using the adherence questionnaire administered by an investigator who had not been involved in the intervention (to avoid information bias in collection of the data). Elderly women who had abandoned their allocated program and were otherwise lost to follow-up were also contacted by the team; a number of these women subsequently visited the Federal University of Minas Gerais to answer the adherence questionnaire.

Successful intervention programs require an adherence rate of more than $85 \%$ to have satisfactory results and ensure internal validity. Therefore, in the present study, elderly women with a participation rate of $85 \%$ or more in the exercise program were considered to have been adherent. ${ }^{31}$ Thus, for a total of 30 sessions, five absences were allowed. Those lost to the program comprised elderly women who did not finish the program or those who missed six or more exercise sessions during the 10 -week intervention.

\section{Statistical analysis}

Three logistic regression models were built for each of the groups to identify factors accounting for adherence of these elderly women with an exercise program. The statistical analysis was blinded, performed without input from the researchers who developed the questionnaire, and without involvement of the study volunteers. The first regression model aimed to identify the contribution of the following explanatory variables: presence of pain, a history of falls, number of comorbidities, self-perception of health, level of stress, cognitive capacity, depressive symptoms, and functional capacity (measured by gait speed, Timed Up and Go test, and Sit-to-Stand test).

The other two regression models assessed the association between 13 motivational items and 12 items that acted as barriers to participation of elderly people in different therapeutic exercise programs. These items constituted the adherence questionnaire.

In the three models, the explanatory variables entered into the model were determined by theoretical reference. To define the variables in the model, the ENTER ${ }^{38}$ method was used and to define the model as significant was defined as $P<0.20$ and alpha $5 \%$. Interpretation of the logistic regression analysis was defined, by the odds ratio (OR), as a relative risk of nonadherence. The level of statistical significance was set at 5\% for all analyses, which were done using Statistical Package for the Social Sciences for Windows version 17.0 software (SPSS Inc, Chicago, IL, USA).

\section{Results}

A total of 382 elderly community-dwelling women participated in this study, comprising 231 in the aerobic exercise group and 151 in the muscle strength training group. The average age in each group was 70.5 years. There were no significant differences between the two groups in terms of clinical or demographic profile. The characteristics of the sample are described in Table 1.

The rate of adherence was $49.70 \%$ in the aerobic exercise group and $56.20 \%$ in the muscle strength training group. The rate of retention in the program was $71.40 \%$ for the aerobic exercise group and $66.80 \%$ for the muscle strength training group. The regression model comprising the ten explanatory variables selected from the theoretical framework did not find any statistically significant differences for the aerobic exercise group $(P=0.947)$ or the muscle strength training group $(P=0.104)$. None of the variables included in the regression model were predictors of adherence in either of the exercise programs.

The multiple logistic regression model comprising motivators for exercise was significant $(P=0.003)$ for the muscle strength training group $\left(R^{2}=0.310\right)$. The variables found to be predictors of adherence were: "Exercises increase my concentration" $(P=0.037$; OR $0.234,95 \%$ confidence interval [CI] 0.012-4.523); "I practice exercises even when I don't 
Table I Characteristics of participants

\begin{tabular}{|c|c|c|}
\hline Characteristics & $\begin{array}{l}\text { Aerobic group } \\
(n=23 I)\end{array}$ & $\begin{array}{l}\text { Strength } \\
\text { group }(n=\mid 5 I)\end{array}$ \\
\hline Age (years), mean (SD) & $70.4(4.64)$ & $70.7(4.9)$ \\
\hline Married, \% (n) & $37.7(87)$ & $33.8(5 \mathrm{I})$ \\
\hline Single, \% (n) & $13.4(3 \mid)$ & $13.9(21)$ \\
\hline Divorced, \% (n) & $8.7(20)$ & $12.6(19)$ \\
\hline Widowed, \% (n) & $40.3(93)$ & $39.7(60)$ \\
\hline \multicolumn{3}{|l|}{ Years of education } \\
\hline$<4, \%$ (n) & $47.1(100)$ & 51.1 (77) \\
\hline $5-8, \%(n)$ & $26.8(62)$ & $23.1(35)$ \\
\hline $9-12, \%(n)$ & $15.6(36)$ & I7.2(26) \\
\hline $13-18, \%(n)$ & $9.5(22)$ & $8.6(13)$ \\
\hline$\geq 19, \%(n)$ & $0.8(2)$ & $0(0)$ \\
\hline Weight (kg), mean (SD) & $69.3(12.7)$ & $70.9(12.6)$ \\
\hline Height (m), mean (SD) & $1.54(6.8)$ & $\mathrm{I} .54(5.7)$ \\
\hline Cardiomyopathy, \% (n) & $12.6(29)$ & $9.3(14)$ \\
\hline Hypertension, \% (n) & $68.4(158)$ & $70.9(107)$ \\
\hline Stroke, \% (n) & $1.7(4)$ & $3.3(5)$ \\
\hline Diabetes, \% (n) & $20.3(47)$ & $23.2(35)$ \\
\hline Arthritis, \% (n) & $36.4(84)$ & $38.4(58)$ \\
\hline Pulmonary disease, \% (n) & $8.7(20)$ & $7.9(12)$ \\
\hline Depression, \% (n) & $22.1(5 \mathrm{I})$ & $19.2(29)$ \\
\hline Osteoporosis, \% (n) & $23.9(55)$ & $22.5(34)$ \\
\hline Urinary incontinence, \% (n) & $20.8(48)$ & $21.9(33)$ \\
\hline Labyrinthitis, \% (n) & $22.9(53)$ & $19.9(30)$ \\
\hline
\end{tabular}

Abbreviation: SD, standard deviation.

feel like it" ( $P=0.004$; OR $0.062,95 \%$ CI $0.009-0.416)$; and "Companions in the group help me to deal with my problems" ( $P=0.024$; OR 0.307, 95\% CI 0.11-0.857).

This multiple logistic regression model comprising motivators for exercise was also significant for the aerobic group $\left(P=0.008 ; R^{2}=0.154\right)$. Variables that predicted adherence were "Exercises increase my concentration" $(P=0.003$; OR 0.598, 95\% CI 0.064-5.622) and "I practice exercise even when I don't feel like it" ( $P=0.05$; OR 0.471, 95\% CI 0.167-1.329).
The third regression model analyzed variables related to barriers to exercise reported by the elderly women. The result was significant only for the muscle strength training group ( $\left.P=0.003 ; R^{2}=0.236\right)$. The variable that predicted adherence was "The bad weather disrupts the accomplishment of the exercises" ( $P=0.001$; OR 5.787, 95\% CI 2.018-16.595).

Although the models did not canvass many variables that were predictors of adherence, the results suggest that there are many barriers to adherence with exercise in the elderly. The main barrier was poor self-perceived health. This was seen in the statement "If my health was better I would be more active". The second most common barrier was difficulty performing exercise due to pain; more than half of the elderly who did not adhere to their program agreed with this statement. The results of these analyses are shown in Table 2.

Among motivating factors, the least important items for participants who did not adhere to their exercise program were the opportunity to have group companions and consideration of physical exercise as a leisure activity. The results of this analysis are shown in Table 3.

The low rate of adherence compared with the rate of retention in the present study indicates that the number of absences among participants was very high. Although the participants in our study did not abandon their exercise program, they found it difficult to attend often enough to reap the benefits of the proposed intervention. On investigating the reasons for nonattendance in each group, we noticed that "Changes in state of health" was the most frequent reason given by adherent and nonadherent participants in both exercise groups. The second most frequent reason given was lack of time. It is also important to highlight that family problems, lack of motivation, and pain were cited markedly more often by elderly women who

Table 2 Descriptive analysis of barriers

\begin{tabular}{|c|c|c|c|c|}
\hline \multirow[t]{2}{*}{ Barriers } & \multicolumn{2}{|l|}{ Aerobic group } & \multicolumn{2}{|l|}{ Strength group } \\
\hline & Adherents (\%) & Nonadherents (\%) & Adherents (\%) & Nonadherents (\%) \\
\hline I feel the same way whether exercising or not & 10.8 & 18.2 & 11.8 & 22 \\
\hline I'm afraid to hurt myself doing exercises & 9.9 & 7.8 & 10.6 & 24 \\
\hline I feel that I have no strength to do exercises & 3.6 & 9.1 & 4.7 & 20 \\
\hline If my health was better, I would be more active & 55.9 & 70.1 & 60 & 66 \\
\hline Not interested in exercises & 9 & 5.2 & 4.7 & 12 \\
\hline It is difficult to exercise when I feel pain & 44. 1 & 53.2 & 38.8 & 58 \\
\hline It is difficult to exercise when I am sad & 15.3 & 13 & 11.8 & 22 \\
\hline Transportation difficulties prevent me doing the exercises & 9.9 & 15.6 & 11.8 & 20 \\
\hline Bad weather disrupts the exercises & 14.4 & 14.3 & 12.9 & 46 \\
\hline I feel very tired when I exercise & $\mathrm{I} \mid .7$ & 23.4 & 10.6 & 20 \\
\hline I am afraid of falling when I exercise & 11.7 & 13 & 9.4 & 16 \\
\hline I have difficulty in performing all exercises & 10.8 & 7.8 & 15.3 & 28 \\
\hline Sample total (\%) & III (59.0\%) & 77 (40.9\%) & $84(62.2 \%)$ & $50(37.3 \%)$ \\
\hline
\end{tabular}

Note: Percent of elderly who reported that the item described was a barrier to the proposed exercise. 
Table 3 Descriptive analysis of motivators

\begin{tabular}{|c|c|c|c|c|}
\hline \multirow[t]{2}{*}{ Motivators } & \multicolumn{2}{|l|}{ Aerobic group } & \multicolumn{2}{|l|}{ Strength group } \\
\hline & Adherents (\%) & Nonadherents (\%) & Adherents (\%) & Nonadherents (\%) \\
\hline Regular exercise improves my health & 98.2 & 97.4 & 95.3 & 100 \\
\hline I prefer to follow an exercise program supervised & 99.1 & 96.1 & 97.6 & 92 \\
\hline I prefer group exercises to at home exercises & 100 & 97.4 & 95.3 & 92 \\
\hline I would like to continue with your exercise program & 95.6 & 97.4 & 97.6 & 94 \\
\hline I feel more prepared when I'm doing physical activity & 99.1 & 93.5 & 98.8 & 100 \\
\hline I am pleased when I exercise & 100 & 97.4 & 98.8 & 100 \\
\hline Exercises improve my concentration & 95.6 & 90.9 & 97.6 & 96 \\
\hline Exercises help me spiritually & 93.9 & 94.8 & 91.8 & 96 \\
\hline I exercise even when I'm not in the mood & 91.2 & 81.8 & 95.3 & 74 \\
\hline Exercise is one of my favorite activities & 76.3 & 80.5 & 88.2 & 68 \\
\hline I feel less pain when I exercise regularly & 95.6 & 93.5 & 89.4 & 86 \\
\hline I'm less stressed when I exercise & 97.4 & 92.2 & 92.9 & 92 \\
\hline The companions of the group help me deal with my problems & 73.7 & 80.5 & 77.6 & 60 \\
\hline Sample total $(\%)$ & I I4 (59.6\%) & 77 (40.4\%) & $84(62.2 \%)$ & $50(37.3 \%)$ \\
\hline
\end{tabular}

Note: Percent of elderly reporting that the item described was a motivator to the proposed exercise.

did not adhere to the program than by those who did adhere. The results of this analysis are show in Table 4.

\section{Discussion}

Participants in the present study showed lower adherence rates than those previously recommended to ensure the effectiveness of therapeutic exercise programs. Thus, completion of an exercise program, or rate of retention in the program, does not mean good adherence or good results.

Health services, community centers, and sports centers that implement exercise programs for the elderly should develop strategies to encourage these people to exercise and increase their frequency of exercise. Brittle et a ${ }^{39}$ reported a high $82 \%$ retention rate in exercise programs for the elderly; however, study participants attended an average of only $43 \%$ of the sessions offered, and only $18 \%$ of the sample participated in all of the sessions prescribed. Thus, it is clear that while the elderly seem to enjoy this kind of physical activity, attendance at sessions offered is not guaranteed.

In our study, the adherence rate was higher in the muscle strength group than in the aerobic exercise group. This finding is consistent with the results of a meta-analysis of 3,389

Table 4 Frequency of reasons for missed sessions in elderly adherent and nonadherent groups in aerobic and strengthening exercise groups

\begin{tabular}{|c|c|c|c|c|}
\hline \multirow[t]{2}{*}{ Reasons for failure } & \multicolumn{2}{|l|}{ Aerobic group } & \multicolumn{2}{|l|}{ Strength group } \\
\hline & Adherents (\%) & Nonadherents (\%) & Adherents (\%) & Nonadherents (\%) \\
\hline Change in health status & 18.9 & 48.1 & 20.2 & 52 \\
\hline Having performed other exercises & 0 & 0 & 0 & 2 \\
\hline Family problems & 9 & 20.8 & 19 & 32 \\
\hline Lack of motivation & 0.9 & 9.1 & 0 & 8 \\
\hline The session is too long & 0 & 0 & 0 & 2 \\
\hline Exercises are uncomfortable & 0 & 3.9 & 0 & 6.0 \\
\hline Exercises are really hard & 0 & 1.3 & 0 & 8 \\
\hline Didn't have the necessary equipment to perform the exercises & 0 & 0 & 1.2 & 2 \\
\hline I did not know exactly how to do the exercise & 0.9 & 0 & 0 & 0 \\
\hline Discouraged & 1.8 & 11.7 & 0 & 12 \\
\hline Lack of time & 9.9 & 14.3 & 13.1 & 32 \\
\hline Lack of interest in the exercises & 0.9 & 1.2 & 0 & 6 \\
\hline Did not understand the instructions given & 0.9 & 0 & 0 & 0 \\
\hline Forgot & 1.8 & 0 & 0 & 6 \\
\hline No company to do the exercises & 0 & 1.3 & 1.2 & 2 \\
\hline Depression or sadness & 1.8 & 6.5 & 1.2 & 12 \\
\hline Lack of adequate supervision by professionals & 0 & 0 & 1.2 & 0 \\
\hline I did not want to do the exercises because I was in pain & 2.7 & 18.2 & 8.3 & 24 \\
\hline Sample total $(\%)$ & III (59.0\%) & $77(40.9 \%)$ & $84(62.2 \%)$ & $50(37.3 \%)$ \\
\hline
\end{tabular}

Note: Percent of elderly who reported missing for the reason described. 
elderly subjects by Hong et al showing that resistance exercise programs had higher rates of adherence than aerobic exercise programs. ${ }^{7}$ In elderly populations, the high prevalence of joint diseases, such as osteoarthritis, frequently hampers successful performance of aerobic exercises because many activities cause joint impact. Muscle strength training exercises without weight-bearing provide more joint stability. ${ }^{7,10}$

Elderly people tend to participate more effectively at the beginning of exercise programs; however, adherence diminishes as time passes. ${ }^{10}$ If health professionals can identify patients at high risk of nonadherence with a proposed treatment, special attention can be given to them during the intervention, and may help to increase their adherence rate..$^{6,10,40}$

In the present study, none of the explanatory variables selected from the theoretical framework were predictors of adherence in our regression models. This result diverges from those of previous studies. In a study reported by Van Heuvelen et al, ${ }^{6}$ a higher number of comorbidities and chronic diseases was correlated to lower adherence of subjects $(n=118)$ to a program of physical exercise. In that study, the participants were divided in two groups, ie, one that carried out physical exercises and another that received a psychological approach. Those in the psychological group who recorded only moderate results for ADL and habitual gait speed before intervention had the lowest program adherence. In the physical activity group, adherence was low for subjects with low ADL scores and modest habitual walking gait scores. Worse functional performance is therefore an impediment to adherence with physical exercise programs in the elderly. ${ }^{6}$

Forkan et $\mathrm{al}^{5}$ also found that changes in health state were a frequent reason for low adherence with continuing exercise regimes among the elderly. ${ }^{5}$ In their study, one of the factors associated with lack of participation $(P<0.05)$ in an exercise program by the elderly was changes in the weather, especially the presence of cold weather. There is no severe winter in Brazil; however, the rainy season brings disruption and we found that this was an important barrier to exercise for participants in the muscle strength training group. This can be explained by the fact that the program was held in the first half of the year when there is a lot of rain, while the aerobic group program was conducted in the second half of the year. With the rain, use of public transport becomes even harder, there is a greater risk of falls, and elderly people struggle with the difficulty of having to walk while holding umbrellas and bags. Hence, they may opt not to leave home.

Understanding the benefits of an exercise program was an important motivator in both the muscle strength training group and the aerobic exercise group in this study. These elderly women mentioned that they practiced their exercises even when they were not in the mood, and realized that exercise was necessary regardless of their mood, indicating their belief in the benefits stemming from the practice. Therefore, educational initiatives highlighting the importance of exercise need to be promoted. ${ }^{8,41}$

One important study found that improved concentration acted as a motivator and predicted adherence with exercise programs, and this could be due to increased circulation in the brain. Concentration can be explained as intense brain activity and research suggests that physical exercise can increase cognitive control and the capacity to pay attention, resulting in better cognitive function. ${ }^{42}$

Socialization, or the presence of other elderly people, was also a predictor of adherence in the muscle strength training group. Exchange of experiences and encountering people with similar problems and similar difficulties, support, listening, and all the other components associated with a group activity are all very important to the benefit of physical exercise in groups. Although individual exercise regimes may bring more directed physical benefits, the benefits of group exercise in terms of social and emotional health are critical and should be encouraged..$^{30,43}$

Our results reflect the difficulties associated with adherence. The present study did not show a direct correlation between low self-rated health and low adherence with exercise programs; therefore, the influencing factors are multifactorial and should be investigated in terms of physical, emotional, and social health. Future qualitative studies are now required to increase our knowledge in this area.

\section{Study limitations}

Although adherence to both programs was suboptimal in this study, some factors may have contributed to the increased adherence rate in relation to the population in general. The elderly women who participated in this study chose to do so and were active and healthy; in other words, they were available for and interested in undertaking physical exercise. Another limiting factor was the short duration of the study; this is because it is difficult to maintain an ideal exercise frequency in long-term exercise programs and adherence rates in such programs are even smaller.

In addition, a factor that could have contributed negatively to the programs developed for this study is the fact that they constituted general exercises and there was no specific individual objective. Preventive exercises are less 
stimulating than exercises that aim to provide relief for a specific health problem.

The scale developed to assess adherence may not have been sensitive enough to identify factors associated with adherence as dichotomous. The volunteer may have answered "yes" or "no" without thinking of any particular situation. A Likert scale could be better. Thus, this may be a limitation in interpretation of the results.

\section{Conclusion}

Future research on adherence with exercise programs for the elderly should incorporate specific strategies; this will increase recruitment rates and boost adherence and retention of people of different cultures and ethnicities in exercise programs. ${ }^{30}$ Future work in this area should focus on behavioral motivation. It is also important to look more broadly at social and environmental contexts and take into account direct variables, such as those related to commitment to exercise among older women, sedentary people, and patients with multiple diseases and functional deficits. ${ }^{44}$ We recommend that older people be asked more directly about what influences them, and qualitative studies should be encouraged in this regard.

\section{Acknowledgment}

The authors appreciate the support of the PRPQ (Search Department), Universidade Federal de Minas Gerais.

\section{Disclosure}

The authors report no conflicts of interest in this work.

\section{References}

1. Veras R. [Envelhecimento Populacional e as Informações De Saúde No Pnad: Demandas e Desafios Contemporâneos]. Cadernos de Saúde Pública. 2007;23(10):2463-2466. Portuguese.

2. Wong LLR, Carvalho JA. [O Rápido Processo de Envelhecimento Populacional do Brasil: Sérios Desafios Para As Políticas Públicas]. Revista Brasileira de Estudos de População. 2006;26(1):5-26. Portuguese.

3. Hughes SL, Seymour RB, Campbell RT, Whitelaw N, Bazzarre T. Bestpractice physical activity programs for older adults: findings from the national impact study. Am J Public Health. 2009;99(2):362-368.

4. Hardage J, Peel C, Morris D, et al. Adherence to exercise scale for older patients (AESOP): a measure for predicting exercise adherence in older adults after discharge from home health physical therapy. J Geriatr Phys Ther. 2007;30(2):69-70.

5. Forkan R, Pumper B, Smyth N, Wirkkala H, Ciol MA, Shumway-Cook A. Exercise adherence following physical therapy intervention in older adults with impaired balance. Phys Ther. 2006;86(3):401-410.

6. Van Heuvelen MJ, Hochstenbach JB, Brouwer WH, de Greef MH, Scherder E. Psychological and physical activity training for older persons: who does not attend? Gerontology. 2006;52(6):366-375.

7. Hong SY, Hughes S, Prohaska T. Factors affecting exercise attendance and completion in sedentary older adults: a meta-analytic approach. J Phys Act Health. 2008;5(3):385-397.
8. Medina-Mirapeix F, Escolar-Reina P, Gascón-Cánovas JJ, MontillaHerrador J, Collins SM. Personal characteristics influencing patients adherence to home exercise during chronic pain: a qualitative study. J Rehabil Med. 2009;41(5):347-352.

9. Kallings L, Leijon ME, Kowalski J, Hellénius ML, Ståhle A. Selfreported adherence: a method for evaluating prescribed physical activity in primary health care patients. $J$ Phys Act Health. 2009;6(4): 483-492.

10. Pisters MF, Veenhof C, Schellevis FG, Twisk JW, Dekker J, De Bakker DH. Exercise adherence improving long term patient outcome in patients with osteoarthritis of the hip and/or knee. Arthritis Care Res. 2010;62(8):1087-1094.

11. Kruger J, Brown DR, Galuska DA, Buchner D. Strength training among adults aged $\geq 65$ years - United States, 2001. MMWR Morb Mortal Wkly Rep. 2004;53(2):25-28.

12. Sluijs EM, Kok GJ, van der Zee J. Correlates of exercise compliance in physical therapy. Phys Ther. 1993;73(11):771-782.

13. Taylor WC, Sallis JF, Lees E, et al. Changing social and built environments to promote physical activity: Recommendations from low income, urban women. Journal of Physical Activity and Health. 2007;4:54-65.

14. Shepich J, Slowiak JM, Keniston A. Do subsidization and monitoring enhance adherence to prescribed exercise? Am J Health Promot. 2007;22(1):2-5.

15. Van Stralen MM, Vries HD, Mudde A, Bolman C, Lechner L. Efficacy of two tailored interventions promoting physical activity in older adults. Am J Prev Med. 2009;37(5):405-417.

16. Bertolucci MO. [Mini-Exame do Estado Mental em uma População Geral]. Arquivos de Neuropsiquiatria. 1994;52(1):1-7. Portuguese.

17. Sampaio IBM. Estatística Aplicada à Instrumentação Animal. 2nd ed. Belo Horizonte, Brazil: Fundação De Estudo E Pesquisa em Medicina Veterinária e Zootecnia; 2002.

18. Podsiadlo D, Richardson S. The timed "Up and Go": a test of basic functional mobility for frail elderly persons. J Am Geriatr Soc. 1991;39(2): $142-148$.

19. Whitney SL, Wrisley DM, Marchetti GF, Gee MA, Redfern JMF. Clinical measurement of sit-to-stand performance in people with balance disorders: validity of data for the five-times-sit-to-stand test. Phys Ther. 2005;85(10):1034-1045.

20. Studenski S, Perera S, Wallace D. Physical performance measures in the clinical setting. J Am Geriatr Soc. 2003;51(3):314-322.

21. Van Iersel MB, Munneke M, Esselink RA, Benraad CE, Olde Rikkert MG. Gait velocity and the timed-up-and-go test were sensitive to changes in mobility in frail elderly patients. J Clin Epidemiol. 2008;61(2):186-191.

22. Lima-Costa MF, Firmo JOA, Uchoa E. [A estrutura da auto-avaliação da saúde entre idosos: projeto bambuí]. Rev Saúde Pública. 2004;38(6): 827-834. Portuguese.

23. Souza MC, Otero UB, Almeida LM, Turci SRB, Figueiredo C, Lozana JA. [Auto-avaliação de saúde e limitações físicas decorrentes de problemas de saúde]. Rev Saúde Pública. 2008;4(4):741-749. Portuguese.

24. Sheikh JI, Yesavage JA. A knowledge assessment test for geriatric psychiatry. Hosp Community Psychiatry. 1985;36(11):1160-1166.

25. Luft CDB, Sanches SO, Mazo GZ, Andrade A. [Versão Brasileira da escala de estresse percebido: tradução e validação para idosos]. Rev Saúde Pública. 2007;41(4):606-615. Portuguese.

26. Lourenço RA, Veras R, Ribeiro CC. [Confiabilidade Teste-Reteste Do Mini-Exame Do Estado Mental em uma população idosa assistida em uma unidade ambulatorial de saúde]. Rev Bras Geriatr Gerontol. 2008;(11):1. Portuguese.

27. Paradela EM, Lourenço RA, Veras R. [Validação da escala de depressão geriátrica em um ambulatório]. Geral Rev Saúde Pública. 2005;39(6):918-923. Portuguese.

28. Batistonil SST, Neril AL, Cupertinoll AFB. [Validade da Escala de Depressão do Center For Epidemiological Studies Entre Idosos Brasileiros]. Rev Saúde Pública. 2007;41(4):598-605. Portuguese. 
29. Findforr MJ, Wyman JF, Gross CR. Predictors of long-term exercise adherence in a community sample of older women. $J$ Womens Health (Larchmt). 2009;18(11):1769-1776.

30. Stineman MG, Strumpf N, Kurichi JE, Charles J, Grisso JA, Jayadevappa R. Attempts to reach the oldest and frailest: recruitment, adherence, and retention of urban elderly persons to a falls reduction exercise program. Gerontologist. 2011;51(1):59-72.

31. Sherrington C, Herbert RD, Maher CG, Moseley AM. A database of randomized trials and systematic reviews in physiotherapy. Man Ther. 2000;5(4):223-226.

32. Henry KD, Rosemond C, Eckert LB, et al. Effect of Number of Home Exercises on Compliance and Performance in Adults Over 65 Years of Age. Physical Therapy. 1998;78(3):270-277.

33. Fritz S, Lusardi M. "White paper: walking speed: the sixth vital sign". J Geriatr Phys Ther. 2009;32(3):2-4.

34. Bohannon RW. Reference value for the Timed Up and Go test: a descriptive metaanalysis. J Geriatr Phys Ther. 2006;29(2):64-68.

35. Macchi CP, Cecchi F, Zipoli R, et al. One-year adherence to exercise in elderly patients. adherence to exercise in elderly patients receiving postacute inpatient rehabilitation after cardiac surgery. Am J Phys Med Rehabil. 2009;88(9):727-734.

36. Lustosa L, Coelho FM, Silva J, et al. The effects of a muscle resistance program on the functional capacity, knee extensor muscle strength and plasma levels of Il-6 and Tnf-in pre-frail elderly women: a randomized crossover clinical trial - a study protocol. Trials. 2010;11:82.
37. Hindin SB, Zelinski EM. Extended practice and aerobic exercise interventions benefit untrained cognitive outcomes in older adults: a meta-analysis. J Am Geriatr Soc. 2012;60(1):136-141.

38. Porteney LG, Watkins MP. Foundations of clinical research: applications to practice. 3rd Ed. Prentice Hall Health. 2008.

39. Brittle N, Patel S, Wright C, Baral S, Versfeld P, Sackley C. An exploratory cluster randomized controlled trial of group exercise on mobility and depression in care home residents. Clin Rehabil. 2009;23(2):146-154.

40. Sjosten M, Salanoja M, Piirtola M, et al. Multifactorial fall prevention programme in the community-dwelling aged: predictors of adherence. Eur J Public Health. 2011;17(5):464-470.

41. Dolansky MA, Stepanczuk B, Charvat JM, Moore SM. Women's and men's exercise adherence after a cardiac event: does age make a difference? Res Gerontol Nurs. 2010;3(1):30-38.

42. Weinberg RS, Gould D. Fundamentos da Psicologia do Esporte e do Exercício. Tradução: Márcia Cristina Monteiro. 3rd ed. Porto Alegre, Brazil: Artmed; 2008.

43. Stathi A, McKenna J, Fox KR. Processes associated with participation and adherence to a 12-month exercise programme for adults aged 70 and older. J Health Psychol. 2011;15(6):836-847.

44. Sullivan-Marx EM, Mangione KK, Ackerson T, et al. Recruitment and retention strategies among older African American women enrolled in an exercise study at a PACE program. Gerontologist. 2011;5(1): 73-81.
Clinical Interventions in Aging

\section{Publish your work in this journal}

Clinical Interventions in Aging is an international, peer-reviewed journal focusing on evidence-based reports on the value or lack thereof of treatments intended to prevent or delay the onset of maladaptive correlates of aging in human beings. This journal is indexed on PubMed Central, MedLine, the American Chemical Society's 'Chemical Abstracts Ser-

\section{Dovepress}

vice' (CAS), Scopus and the Elsevier Bibliographic databases. The manuscript management system is completely online and includes a very quick and fair peer-review system, which is all easy to use. Visit http://www.dovepress.com/testimonials.php to read real quotes from published authors. 